\title{
Forma E CONTEXTO NA LinguísticA do TeXto de Eugenio Coseriu
}

\author{
Form and Context in Eugenio Coseriu's Textual \\ Linguistics*
}

\author{
Iara Bemquerer Costa**
}

\section{INTRODUÇÃo}

Os estudos sobre Linguística do Texto publicados por Eugenio Coseriu (1921-2002) na segunda metade do século XX foram recentemente objeto de duas cuidadosas publicações na Espanha: Coseriu \& Lamas (2006) e Coseriu (2007). Este artigo resulta da leitura dos dois livros.

O tema discutido aqui não reflete as questões que Eugenio Coseriu enfatizou e aprofundou em seus trabalhos sobre a Linguística do Texto; pelo contrário, para recuperar a concepção do autor sobre a relação entre forma e contexto é necessário reunir e relacionar elementos que se encontram dispersos em seus estudos. A tentativa que fazemos de sistematizar a relação entre forma e contexto para Coseriu parte de um olhar externo, ou seja, da busca de interlocução na perspectiva de uma tradição já bem consolidada na área, para a qual a relação entre forma e contexto tem uma relevância significativa. Para sintetizar alguns pressupostos da vertente da Linguística Textual tomada como referência teórica para a discussão da abordagem adotada por Coseriu, vamos recorrer a uma formulação esclarecedora do conceito de texto e do papel do contexto na construção do sentido:

\begin{abstract}
Um texto se constitui enquanto tal no momento em que os parceiros de uma atividade comunicativa global, diante de uma manifestação linguística, pela atuação conjunta de uma complexa rede de fatores de ordem situacional, cognitiva, sociocultural e interacional, são capazes de construir, para ela, determinado sentido.
\end{abstract}

\footnotetext{
Trabalho apresentado no simpósio Coseriu: memória e atualidade, integrado ao $X \mathrm{~V}$ Congresso Internacional de La ALFAL: Universidad de la República (Montevideo, Uruguay), 18-21 de agosto de 2008 .

** $\quad$ Universidade Federal do Paraná
} 
Portanto, à concepção de texto aqui apresentada subjaz o postulado básico de que o sentido não está no texto, mas se constroi a partir dele, no curso de uma interação. Para ilustrar essa afirmação, tem-se recorrido com frequência à metáfora do iceberg: como este, todo texto possui apenas uma pequena superfície exposta e uma imensa área imersa subjacente. Para se chegar às profundezas do implícito e dele extrair um sentido, faz-se necessário o recurso a vários sistemas de conhecimento e a ativação de processos e estratégias cognitivas e interacionais.

Uma vez construído um - e não o - sentido, adequado ao contexto, às imagens recíprocas dos parceiros da comunicação, ao tipo de atividade em curso, a manifestação verbal será considerada coerente pelos interactantes. (KOCH, 1997, p. 25, grifos da autora)

Nesta perspectiva, considera-se uma concepção de texto não como produto, ou o registro verbal de um evento comunicativo, mas como um processo, em que estão envolvidos interlocutores engajados em eventos de interação historicamente situados. Decorre desta concepção a importância de incorporar fatores pragmáticos e contextuais às análises, uma vez que tanto as informações sobre os interlocutores e o contexto sócio-histórico em que os textos foram produzidos quanto as características formais assumem um papel relevante na construção do sentido. Assim, parte-se do pressuposto de que a busca de um conjunto de marcas formais, capazes de garantir a textualidade de sequências verbais produzidas nas mais diversas circunstâncias, seja insuficiente para o estudo do texto.

Outro pressuposto é de que a diversidade das características dos textos está relacionada à variabilidade de suas formas e usos, ou seja, aos gêneros textuais. Estes refletem os processos históricos que criam as condições para o surgimento, padronização (tipificação), estabilidade ou modificação de uma variedade potencialmente infinita de gêneros. Para a análise dos gêneros textuais são relevantes tanto as características sociocomunicativas quanto as propriedades formais (cf.: MARCUSCHI, 2005).

A Linguística Textual leva em conta também a possibilidade de agrupar textos ou fragmentos de textos (sequências cf. ADAM, 2001) a partir da recorrência de propriedades formais. O conceito de tipo de texto, aplicável em especial às sequências, permite reconhecer semelhanças e diferenças entre partes de textos, mediante a análise de suas formas prototípicas de organização e do uso recorrente de determinados recursos linguísticos. A partir desse quadro, os estudos sobre a construção do texto incorporam o gênero e/ou o tipo textual às categorias de análise.

A importância dos elementos formais e contextuais nessa concepção de texto nos motivou a explorar esse tema na interlocução com os pressupostos da Linguística do Texto considerados por Coseriu. Para isso, o ponto de partida óbvio e necessário é a concepção do autor sobre os níveis do falar e a articulação entre esses níveis. Somente após situar os estudos 
textuais no modelo formulado pelo autor será possível centrar a atenção nas premissas mais relevantes de sua concepção de Linguística do Texto. Essas duas etapas da exposição constituem os passos preliminares antes de colocar em foco a questão que nos interessa aqui: o papel dos elementos formais e contextuais na teoria do texto coseriana.

A posição do autor perante essa questão é fortemente influenciada pela relevância dos textos literários em seus estudos. Coseriu (2007, p. 245) admite que a linguagem literária "deverá ser considerada como a linguagem por excelência, já que só ela apresenta desenvolvimento pleno de todas as possibilidades linguísticas", sendo as demais modalidades (linguagem corrente e científica, por exemplo) avaliadas como desvios ou reduções em relação à linguagem em pleno desenvolvimento.

\section{O LUGAR DA Linguística do TEXTO NOS Estudos DA LinguAgEM}

Segundo Coseriu (2007, p. 128), a complexidade dos estudos textuais deve-se inicialmente à dupla posição que o texto ocupa nos estudos da linguagem. $O$ texto se apresenta, primeiramente, como o último nível da estruturação das línguas. $O$ autor reconhece seis níveis hierarquizados nessa estruturação: elementos mínimos, palavra, grupo de palavras, cláusula, sentença, texto. Mas considera também o texto como um nível autônomo no domínio do falar como atividade humana universal. Nessa segunda perspectiva, cada um dos níveis é determinado pelos níveis anteriores, mas tem também autonomia para, em certas circunstâncias, suspender a atuação dos princípios dos níveis superiores.

Coseriu (2007, p. 130) considera que o falar apresenta três níveis autônomos: 1) o nível universal da linguagem ou nível do falar em geral; 2) o nível histórico das línguas; 3) o nível individual dos textos. O Quadro 1 mostra a relação hierárquica entre eles e situa o texto nos níveis histórico e individual.

\section{QUADRO 1 - O LUGAR DO TEXTO NOS ESTUDOS LINGUÍSTICOS \\ NÍVEIS DO FALAR \\ Nível universal: o falar em geral (linguagem) \\ Nível histórico: a língua (tradição histórica do falar) \\ Nível individual: o texto \\ GRAUS DO SABER LINGUÍSTICO

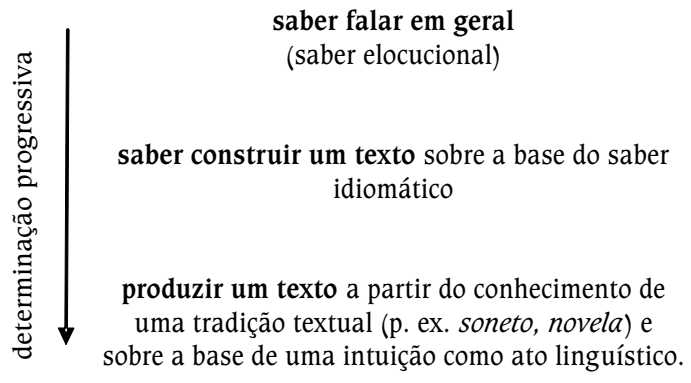

FONTE: Adaptado de Coseriu (2007, p. 128) 
O nível universal diz respeito aos fenômenos comuns a todas as línguas e, segundo o autor, contempla dois fatos muito gerais, o primeiro sobre a natureza das línguas, o segundo sobre os falantes. A primeira propriedade universal das línguas é seu caráter sígnico, ou seja, a possibilidade de referir-se a algo que não se identifica com a língua em si. A comparação entre as línguas fornece uma evidência para essa propriedade: diferentes línguas correspondem a configurações distintas para uma mesma realidade extralinguística. Algumas atividades relacionadas à linguagem, como a tradução, por exemplo, só são possíveis a partir do pressuposto de que diferentes línguas podem referir-se a uma mesma realidade e o fazem de forma diferenciada.

A segunda propriedade que Coseriu atribui ao nível universal da linguagem "é a faculdade universal de falar, não determinada historicamente, que todos, como falantes, possuímos" (COSERIU, 2007, p. 131). Esta capacidade contempla duas classes de fatos. A primeira refere-se aos princípios gerais do pensamento dados intuitivamente, como o da identidade e o da não contradição. Os falantes não são capazes de formular conscientemente esses princípios a partir da reflexão, embora não tenham dificuldade de empregá-los ao falar. Uma evidência para o princípio da identidade é a possibilidade de que o falante volte a referir-se a algo já mencionado mediante o uso de pronomes, o que se baseia na pressuposição de que a identidade do que foi designado se mantém nas retomadas posteriores feitas com o uso de formas pronominais. A segunda classe de fatos apresentada pelo autor é o conhecimento da realidade. Ao falar, fazemos referência a um estado de coisas considerado normal, ao conhecimento que o homem tem de si mesmo e do mundo: fatos como a existência de um sol e uma lua, os dias e as noites se alternarem, o homem ter dois braços e duas pernas.

Coseriu formula nos seguintes termos a avaliação dos atos linguísticos sob o ponto de vista do nível universal da linguagem:

Se o falar responde às expectativas esperáveis em relação ao primeiro grau, o saber elocucional, pode ser qualificado como congruente. Será um falar claro, consequente e conexo, sobretudo no que se refere aos princípios gerais do pensar [...]; e se fundará no conhecimento das "coisas" - em pressuposições, em geral [...]. o termo congruente, portanto, faz referência a tudo o que não depende nem do conhecimento de uma determinada língua nem da capacidade de construir textos (COSERIU, 2007, p. 144).

O segundo nível autônomo do falar é o nível histórico das línguas. Cada língua particular dispõe de um léxico estruturado de forma diferente, possui sua própria gramática e seu sistema fonológico: "No nível histórico, 
a que corresponde o saber idiomático, fala-se de correção. Uma expressão é correta quando se ajusta às regras de um determinado idioma." (COSERIU, 2007, p. 145).

Coseriu considera também que o nível individual dos textos é autônomo em relação ao nível histórico das línguas. São vários os argumentos mobilizados para dar sustentação a esse ponto de vista:

a) Embora em geral os textos sejam compostos em uma só língua, isso não é uma condição necessária, já que um me s mo texto pode mesclar elementos de duas ou mais línguas.

b) As regras da língua podem ser suspensas no texto sem provocar sua rejeição, pois o desrespeito a essas normas, quando motivado, é aceitável. Por exemplo, a violação às normas da língua pode ser usada para caracterizar a fala de um estrangeiro; ou a sintaxe pode ser significativamente alterada na linguagem telegráfica.

c) Os textos são influenciados pelos universos de discurso, o que não acontece com as línguas. São diferentes os textos constituídos no universo da literatura, das ciências, da mídia, da mitologia.

d) Os textos são também influenciados pela situação em que são produzidos.

e) Os textos têm tradições particulares, diferentes das tradições das línguas históricas. Há classes de textos - ou gêneros - que têm uma tradição própria, não identificada com a tradição de uma língua apenas. Isso pode ser observado tanto na literatura (o romance, o soneto, a comédia) como em gêneros de circulação cotidiana (a notícia jornalística, o artigo científico, a entrevista).

Segundo o autor: "No nível do texto, a que corresponde o saber expressivo, fala-se de adequação: algo pode ser adequado ou inadequado com inteira independência de que seja correto ou incorreto." (COSERIU, 2007, p. 145 , grifos do autor).

O autor compara os três níveis do falar recorrendo a um conjunto de critérios: o tipo de conteúdo próprio de cada um, o tipo de conhecimentos que cada nível presupõe, os parâmetros para sua avaliação. É o que sintetizamos no Quadro 2, elaborado a partir de formulações encontradas em Coseriu (2007). 


\section{QUADRO 2 - COMPARAÇÃO ENTRE OS NÍVEIS DO FALAR}

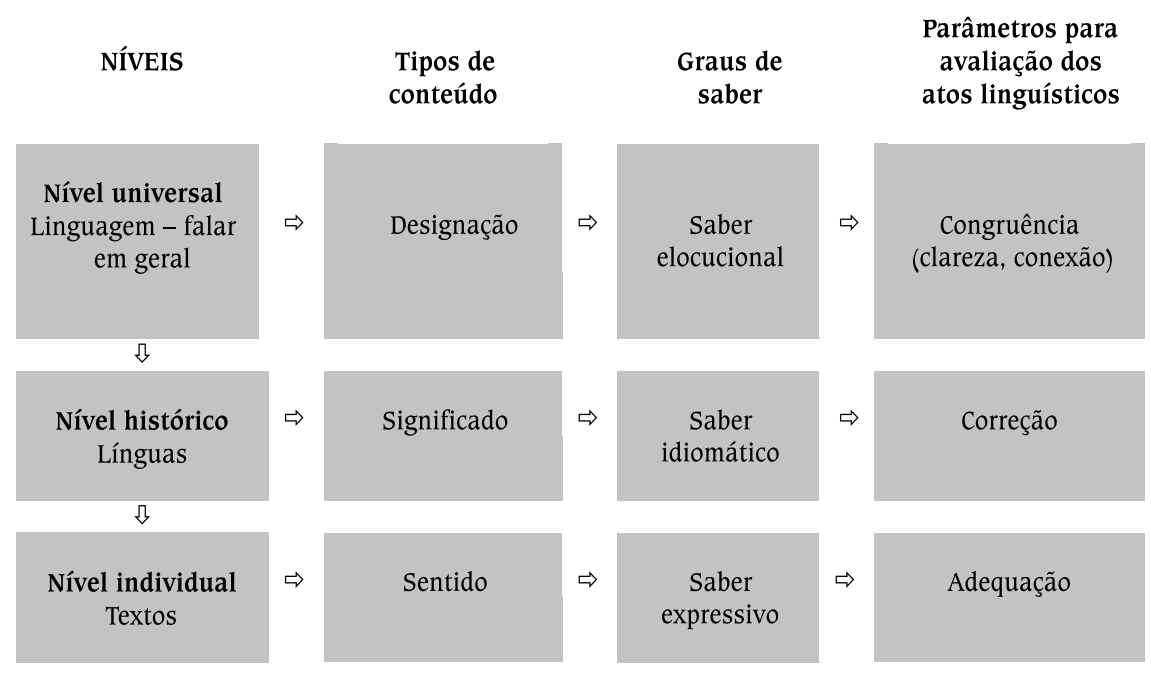

O autor considera que cada nível é autônomo em relação ao nível superior. Uma consequência lógica desse esquema é vincular a Linguística do Texto ao terceiro nível, que corresponde ao saber expressivo. Mas a questão é um pouco mais complexa, como discutiremos a seguir.

\section{PRINCIPAIS PREMISSAS DA LINGUística Do TEXTO}

Com o rigor que lhe é peculiar, Coseriu procura formular os princípios de uma Linguística do Texto consistente com sua concepção dos níveis do falar. Como o teórico considera a autonomia entre os três níveis, a Linguística do Texto está associada ao terceiro nível, o nível individual, e é caracterizada como uma Linguística do sentido. Essa área tem como meta a hermenêutica do sentido dos textos e se fundamenta em uma teoria da interpretação.

Ao adotar essa posição, Coseriu tem clareza de que sua concepção de Linguística do Texto é consideravelmente diferente dos trabalhos dominantes nesta área, mas faz questão de enfatizar que a abordagem que tem como objeto a hermenêutica do sentido é "a 'verdadeira' e 'própria' Linguística do Texto" (COSERIU, 2007, p. 156).

Por outro lado, o autor reconhece também a existência nas línguas particulares de formas usadas especificamente para a expressão de funções textuais, as quais só podem ser adequadamente estudadas no nível do texto e não da sentença. Admite ainda a existência de estudos dentro de uma tradição da Linguística do Texto diferente da sua, que se ocupam exatamente 
dos elementos de que as línguas particulares dispõem para a construção dos textos. Finalmente, reconhece a universalidade (empírica e não lógica) dos procedimentos específicos para a expressão de funções textuais:

\begin{abstract}
A respeito do texto, que é o nível que interessa aqui, já se estabeleceu uma primeira comprovação fundamental: não se trata de um nível da estruturação gramatical de uma língua racionalmente necessário, pois uma língua continuaria sendo uma língua ainda que não dispusesse de procedimentos específicos para a constituição de textos, ou seja, para a expressão de funções textuais. [...] Acontece, no entanto, que todos os idiomas conhecidos até o momento parecem comprovar a existência desse tipo de procedimentos, de modo que o texto, como nível de estruturação idiomática, pode ser considerado, pelo menos provisoriamente, como um universal empírico (COSERIU, 2007, p. 308, grifos do autor).
\end{abstract}

Assim, mesmo sem aderir a uma tradição já consolidada, Coseriu admite a possibilidade de se ter não apenas uma, mas duas concepções de Linguística do Texto, associadas a níveis diferentes do falar, conforme o esquema abaixo:

\title{
QUADRO 3 - AS CONCEPÇÕES DE LINGUÍSTICA DO TEXTO E SEU LUGAR NO ESTUDO DO FALAR
}

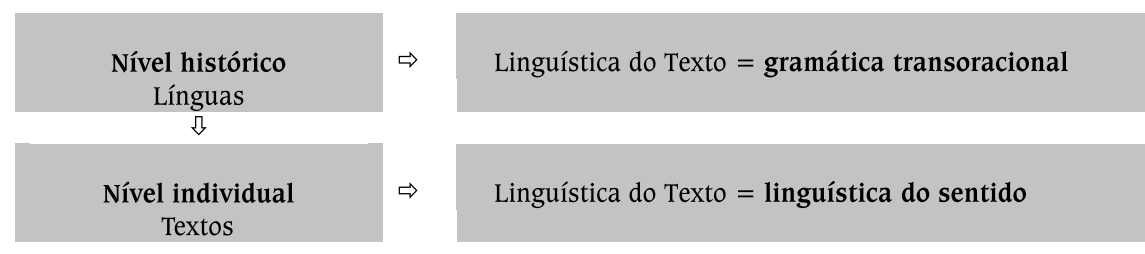

Como nosso interesse é investigar o papel da forma e do contexto na perspectiva de Coseriu, vamos discutir a questão em cada uma das concepções de Linguística do Texto.

\section{A Linguística do TEXTo como GramáticA TRANSORACIONAL}

Segundo Coseriu, todos os níveis da estruturação gramatical das línguas apresentam quatro propriedades: superordenação, subordinação, coordenação e substituição. Portanto, para verificar se o nível textual constitui um nível a mais da estruturação gramatical das línguas é necessário examinar se esse nível apresenta as mesmas propriedades encontradas nos demais níveis. Passemos inicialmente à definição das quatro propriedades: 
a) Superordenação: "possibilidade de que unidades que, por sua constituição, pertencem a um nível inferior funcionem 'substitutivamente' em um nível superior (por exemplo, que uma palavra funcione como oração)" (COSERIU, 2007, p. 309);

b) Subordinação: "possibilidade de que unidades que, por sua constituição, pertencem a um nível superior funcionem 'substitutivamente' em um nível inferior (por exemplo, que o grupo de palavras funcione como uma só palavra)" (COSERIU, 2007, p. 309);

c) Coordenação: possibilidade de que as unidades de um nível sejam conectadas entre si;

d) Substituição: possibilidade de que uma unidade possa ser substituída por uma proforma, seja anafórica, seja cataforicamente.

o Quadro 4 faz uma representação esquemática dessas quatro propriedades.

QUADRO 4 - PROPRIEDADES DOS NÍVEIS DA ESTRUTURAÇÃO GRAMATICAL

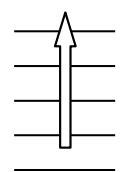

superordenação

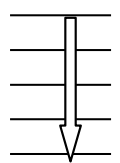

subordinação

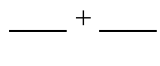

coordenação

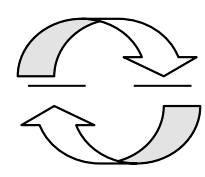

Substituição

FONTE: Coseriu (2007, p. 310)

Segundo Coseriu (2006, p. 325), para examinar se o nível do texto pode ser tratado como um nível da gramática das línguas, é necessário verificar se este nível exibe três entre as quatro propriedades encontradas em qualquer nível da gramática. São três, e não quatro, porque o nível da superordenação não se aplica ao texto, uma vez que esse seria o nível mais alto da gramática, o que impossibilitaria seu alçamento a um nível superior.

O autor constata que as três propriedades em questão subordinação, coordenação e substituição - estão claramente presentes no nível textual.

Em primeiro lugar, observa-se a propriedade da subordinação, isto é, a possibilidade de incorporar textos dentro de textos. É o que ocorre 
nas citações. $O$ texto pode funcionar como sentença, quando sentenças de um texto são incorporadas a outro, ou como partes de sentenças, quando o autor faz uso do discurso indireto ou do discurso indireto livre. As línguas dispõem de recursos formais usados especificamente para incorporar textos, como discursos diretos ou indiretos. Tal característica pode ser facilmente observada no português.

No exemplo (1), além das aspas usadas para delimitar a citação direta, estão presentes expressões usadas para identificar o texto citado: seu título ("O espelho"), autor (Machado de Assis), gênero (conto). O verbo de dizer "continuar" também funciona como um delimitador entre o texto de Toledo e o de Machado de Assis.

(1) "Cada criatura humana traz duas almas consigo: uma que olha de dentro para fora, outra que olha de fora para dentro." Reunido em torno de uma mesa, um grupo de jovens lê o conto O Espelho, de Machado de Assis. Cada um lê um trecho e cede a vez para o jovem ao lado continuar. "Está claro que o ofício dessa segunda alma é transmitir a vida, como a primeira; as duas completam o homem, que é, metafisicamente falando, uma laranja." A prosa de Machado vai circulando em volta da mesa. [...] (Roberto Pompeu de Toledo. Veja, 01 fev. 2006).

A coordenação, segunda propriedade examinada, também tem formas específicas de expressão nas diversas línguas. Há expressões que coordenam blocos inteiros do texto: por um lado... por outro lado...; em primeiro lugar... além disso... finalmente... portanto...

As línguas contêm também elementos específicos que fazem as substituições textuais, como os verbos que funcionam como proformas ou os pronomes que sintetizam partes dos textos. Pode-se observar o uso de uma dessas formas no exemplo abaixo:

$$
\begin{aligned}
& \text { - O candidato ao governo do Estado já foi aprovado na } \\
& \text { convenção do partido? } \\
& \text { - Ainda não. }
\end{aligned}
$$

No exemplo (2) a proforma "ainda não" faz a substituição de parte do enunciado anterior e deve ser interpretada como "O candidato ao governo do Estado ainda não foi aprovado na convenção do partido." Em (3) a proforma "isso" substitui todo o enunciado anterior. 
(3) A umidade do ar continua muito baixa na maioria dos estados e os índices de poluição continuam elevados. Isso tem aumentado os atendimentos a pacientes com problemas respiratórios.

Ao examinarmos a relação entre os elementos formais e contextuais nessa primeira concepção, constatamos que a Linguística do Texto como gramática transoracional contempla unicamente a contribuição dos elementos formais para a construção textual. A primeira evidência para isso é o nível do falar no qual Coseriu enquadra essa concepção. Ao colocá-la no nível histórico das línguas, exclui as questões relacionadas ao uso individual e à caracterização de textos particulares. Seu objeto de estudo é a identificação das formas de que as línguas particulares dispõem para expressar no texto a subordinação, a coordenação e a substituição, bem como a caracterização das condições de uso de tais formas.

Qualquer análise sobre o contexto, seja linguístico ou extralinguístico, implica a observação da linguagem em uso. A Linguística do Texto concebida como gramática transoracional não tem como objeto o estudo dos textos em si, como produções históricas individuais, mas o potencial disponível nas línguas para que os textos possam ser produzidos. Está, portanto, centrada no estudo das formas. A contribuição do contexto está presente apenas para a caracterização das condições de uso das formas disponíveis em uma língua particular para a construção de textos. Poderia tratar, por exemplo, das condições contextuais que poderiam levar à escolha do verbo de dizer "advertir" no enunciado (4), em oposição ao verbo "informar" em (5):

(4) O ministro da saúde advertiu a população sobre os riscos de uma nova epidemia de dengue.

(5) O ministro da saúde informou à população sobre os riscos de uma nova epidemia de dengue.

Para a Linguística do Texto como gramática transoracional não interessa se as sentenças (4) e (5) foram ou não efetivamente produzidas, ou como o discurso do ministro foi citado no discurso do jornalista. Esses exemplos são apenas ilustrações para analisar as condições nas quais as escolhas dos verbos de dizer "advertir" ou "informar" seriam usados "corretamente", ou seja, segundo as regras de uso desses verbos no português. 


\title{
A Linguística do TeXto como Linguística do Sentido
}

A concepção de Linguística do Texto como Linguística do sentido é proposta por Coseriu como a verdadeira Linguística do Texto, a abordagem à qual ele adere claramente. Segundo o autor, "o objeto fundamental de uma Linguística do Texto como Linguística do sentido são os procedimentos de criação e compreensão do sentido." (COSERIU, 2007, p. 157). Assim, para compreender a definição do objeto de estudo da Linguística do Texto para Coseriu, é necessário inicialmente voltar aos três tipos de conteúdo associados aos níveis do falar, conforme mostramos esquematicamente no Quadro 2: a designação (nível universal da linguagem), o significado (nível histórico das línguas) e o sentido (nível individual dos textos).

A designação é entendida como a propriedade que todas as línguas têm de referir-se à realidade extralinguística. Já o significado é entendido como formas de representação específicas das línguas particulares.

\begin{abstract}
Em resumo, pode-se dizer que o conjunto das funções da linguagem em geral (= do falar em geral), isto é, o conjunto das funções que se referem à designação de objetos e estados de coisas objetivas, pode ser entendido como um tipo de conteúdo linguístico: esse tipo de conteúdo se chama designação. o conjunto do que uma língua expressa como tal, isto é, o conjunto do que pode ser entendido apenas por meio da língua, pode ser considerado, por sua vez, como um tipo diferente de conteúdo linguístico: este conteúdo denomina-se significado (COSERIU, 2007, p. 152).
\end{abstract}

O sentido diz respeito ao conjunto de conteúdos que só existem como conteúdos de textos: "a designação e o significado, isto é, o que os signos linguísticos designam e aquilo que significam em uma determinada língua, formam no texto a expressão de uma unidade de conteúdo superior de natureza mais complexa: o sentido." (COSERIU, 2007, p. 153).

Para Coseriu, a tarefa da Linguística do Texto é hermenêutica. Seu objetivo é comprovar e justificar o sentido dos textos. Estes têm um caráter particular, individual, e correspondem ao último nível dos fenômenos da linguagem. Assim, ao comprovar e justificar o sentido dos textos particulares, o linguista só pode chegar a um tipo de generalização: a identificação de universais empíricos, ou seja, das características comuns a vários textos (ou até mesmo a todos os textos). Ao buscar as generalizações acerca das formas que o sentido assume nos textos, a Linguística do Texto pode se identificar com a teoria da investigação das classes de textos. Para Coseriu (2007, p. 302), essa abordagem não coincide simplesmente com a teoria dos gêneros, mas a engloba. 
Por seu caráter hermenêutico, a Linguística do Texto tem uma metodologia e uma heurística que correspondem à tarefa de fazer o registro exaustivo do que se pode esperar nos textos, um inventário dos tipos comprovados e possíveis de sentido e dos procedimentos que os sustentam nos discursos analisados. Trata-se de um registro aberto: novos textos podem revelar novos procedimentos e tipos de sentido.

Coseriu prevê uma delimitação no conjunto de textos que seriam objeto de estudo da Linguística do Texto. Ele propõe que esta área dos estudos da linguagem tenha como objeto prioritário os textos literários e justifica nos seguintes termos sua opção:

\begin{abstract}
A linguagem literária, portanto, não pode ser uma modalidade de uso linguístico a mais, quer dizer, não se encontra no mesmo nível que outras modalidades, como a linguagem corrente ou a linguagem científica; em vez disso, deverá ser considerada como a linguagem por excelência, já que só ela apresenta o desenvolvimento pleno de todas as possibilidades linguísticas. [...]

Deve-se considerar a linguagem poética como linguagem em sua plena funcionalidade. A poesia, não no sentido mais restrito, mas no sentido de arte literária, é o lugar do desenvolvimento pleno e total da funcionalidade da linguagem. O uso poético da linguagem não é nenhum desvio em relação ao uso "normal", senão, ao contrário, todas as demais modalidades da linguagem, como a linguagem corrente, científica, etc. (seria mais apropriado falar de "modo de falar científico", "modo de falar orientado a fins práticos", etc.) representam desvios em relação ao falar em seu pleno desenvolvimento, ou seja, em relação à linguagem enquanto tal. Só é lícito falar de redução no caso das diversas modalidades do uso linguístico não poético, porque é nelas que se suspendem ou "desatualizam" muitas funções linguísticas que, em sua máxima potência, estão presentes no falar literário; pode-se dizer que no falar orientado para fins práticos de algum modo nos dirigimos "através do signo" diretamente à "coisa" designada, que é o verdadeiramente importante (COSERIU, 2007, p. 245)
\end{abstract}

A prioridade que Coseriu confere ao texto literário como objeto de estudo é, provavelmente, o ponto que o leva a um maior distanciamento em relação à Linguística do Texto constituída a partir de outra tradição. As tendências da Linguística de Texto atualmente vão na direção oposta à apontada por ele. Primeiramente se observa o uso da categoria de gênero textual como um recorte inicial a partir do qual se busca observar as propriedades internas dos textos. Nessa perspectiva, nenhum gênero textual é considerado modelar para os demais: o que interessa observar são as condições de surgimento, circulação e estabilização dos gêneros e das características próprias a cada gênero (características temáticas, 
composicionais e estilísticas, para ficar nas propriedades apontadas por Bakhtin, 1992). Os estudos textuais têm procurado também acompanhar a tendência de produção de textos da mídia e da internet, marcados pela não linearidade (hipertexto) e pelo uso de múltiplos recursos (multimodalidade).

$\mathrm{Na}$ abordagem de Coseriu, a Linguística do Texto não se limita ao estudo dos textos literários, mas este é seu objeto prioritário. Além disso, os textos literários fornecem os parâmetros para estudo dos textos não literários: "No entanto, na medida em que todos os textos têm sentido, não apenas os literários, a Linguística do sentido se ocupa também dos textos não literários, particularmente das reduçóes das possibilidades de sentido que se pode reconhecer neles" (COSERIU, 2007, p. 300, grifo nosso). Esta afirmação destaca dois pressupostos importantes da concepção de Linguística do Texto para Coseriu. Destaca, primeiramente, que esta área tem como objeto preferencial textos escritos, ou, mais precisamente, uma modalidade apenas de textos escritos, os literários. Os textos não literários são avaliados como manifestações que fazem um uso reduzido das possibilidades expressivas da linguagem e que não devem ser o objeto prioritário de estudo.

Um último pressuposto relevante para o autor é a importância do extralinguístico para a expressão do sentido: "Na medida em que o sentido se expressa nos textos não apenas linguisticamente, mas também extralinguisticamente - e isto em uma metida considerável -, a 'verdadeira' e 'própria' Linguística do Texto deve ir além do linguístico." (COSERIU, 2007, p. 304). Este pressuposto sugere a importância do estudo do contexto como um elemento que contribui para a expressão do sentido do texto.

\section{As Contribuições da Forma E do Contexto na Linguística TEXTUAL COMO HERMENÊUTICA Do SENTIDO}

Na formulação do seu modelo de Linguística do Texto, Coseriu trata de forma bastante detalhada a questão do contexto. Ele estabelece, inicialmente, uma distinção entre os conceitos de situação (continuum espaçotemporal que se constrói em torno do falante no ato de fala), região (espaço geográfico dentro do qual o signo funciona em determinados sistemas de significação), contexto (realidade complexa que rodeia um signo) e universo do discurso (sistema universal de significações a que pertence um discurso). Indica também que o contexto pode ser verbal (constituído por outros signos) ou extraverbal, tipo que comporta vários subtipos:

a) Físico: coisas que estão à vista do falante;

b) Empírico: objetos e estados de coisas conhecidos pelos interlocutores; 
c) Natural: o universo empírico conhecido pelos falantes;

d) Prático ou ocasional: a conjuntura particular objetiva ou subjetiva do discurso;

e) Histórico: conjunto de circunstâncias históricas conhecidas pelos falantes;

f) Cultural: tudo o que pertence à tradição cultural de uma comunidade. (COSERIU, 2007, p. 222-228)

Esta síntese da concepção de contexto nos trabalhos de Coseriu mostra, por um lado, sua preocupação com uma formulação abrangente, que permita captar a noção de contexto a partir de recortes diversos, desde as condições espaçotemporais em que o falante produz o seu discurso até $o$ universo discursivo tomado como referencial para a produção de um discurso. Uma peculiaridade importante é que a formulação de todos os tipos de contexto tem um elemento constante: o ponto de referência é sempre o signo linguístico (equivalente grosso modo ao conceito de palavra) em relação a outros signos ou a elementos não linguísticos. Observa-se a relação do signo com outros signos da língua; com os signos que o antecedem e sucedem; com o meio geográfico em que circula; com o contexto físico imediato em que o discurso é produzido, etc.

A maneira como os elementos formais - os signos - se relacionam aos diversos tipos de contextos para a produção/interpretação do sentido dos textos é uma questão que só podemos esclarecer mediante as análises de textos apresentadas pelo autor. Para isso, escolhemos primeiramente a análise que o autor faz de D. Quixote, de Cervantes. Em seguida, para esclarecer questões apontadas nessa análise e explicitar o papel da forma e contexto nos textos literários e não literários, vamos comentar o ensaio "Informação e literatura" (COSERIU, 2006, p. 85-99).

Coseriu reconhece que a abordagem do texto que mais se aproxima da Linguística do Texto como hermenêutica do sentido é a estilística. A análise da novela $D$. Quixote é apresentada para exemplificar a abordagem estilística de Leo Spitzer e propor alterações na análise que mostrem a metodologia de análise da Linguística do Texto.

A análise que Spitzer faz de $D$. Quixote aponta como característica fundamental da novela de Cervantes a instabilidade dos nomes dos personagens. Esta propriedade, que chama a atenção do leitor imediatamente, é tomada como um indício importante para o sentido global da novela. Coseriu (2007, p. 267) resume nos seguintes termos a análise feita por Spitzer: 
O homem não pode compreender por si mesmo a essência das coisas: na medida em que ele também é uma criação, como sujeito só pode ver as coisas de forma relativa, ou seja, "a partir de sua própria perspectiva”. Seria necessário reconhecer, segundo Spitzer, que "a superabundância de nomes, de palavras e de línguas, a polionomasia, a polietimologia e o poliglotismo nos permitiram chegar ao perpectivismo linguístico do artista Cervantes, que sabe muito bem que a transparência da linguagem só é uma realidade para Deus".

Coseriu apresenta a análise estilística que Spitzer faz de D. Quixote como ponto de partida para expor sua teoria da articulação do sentido. Argumenta que esta análise capta apenas o sentido parcial da novela de Cervantes, porque toma como ponto de partida um indício apenas, sem analisar os diversos estratos da articulação do sentido. A teoria da interpretação (hermenêutica) considera que o sentido dos textos, tal como o sentido das frases, não é simplesmente a soma do sentido de suas partes:

Definitivamente, seria necessário estudar com profundidade quais são os elementos das unidades de sentido complexas e como se assentam para formar unidades de sentido de categoria superior. Isso mostraria uma progressão desde uma unidade mínima, ainda não definida, ao parágrafo, deste ao capítulo, e do capítulo à obra inteira (COSERIU, 2007, p. 264, grifos do autor).

Este modelo pode ser representado a partir do seguinte esquema:

QUADRO 5: ARTICULAÇÃO HIERÁRQUICA DO SENTIDO

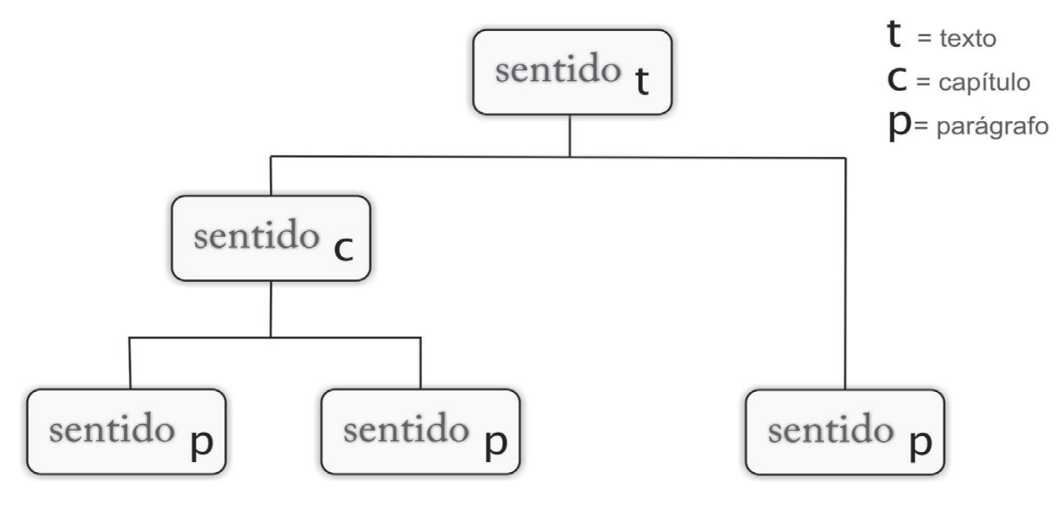

FONTE: Coseriu (2007, p. 271) 
Coseriu busca então encontrar o sentido da novela $D$. Quixote a partir da articulação hierárquica do sentido das diversas partes. Segundo ele, a instabilidade dos nomes é um fator entre outros, e deve ser compreendida em sua conexão com as demais características importantes para a interpretação do sentido da novela. Este resulta da análise integrada do sentido de partes do texto:

a) Os nomes dos personagens são instáveis;

b) D. Quixote fala muito e com entusiasmo da liberdade;

c) Uma das atividades preferidas de D. Quixote é libertar distintos personagens;

d) O estranho governo de Sancho Pança sobre a ilha Baratária é uma variação burlesca sobre a utopia e o estado ideal e também faz parte do tema da liberdade.

A conclusão, após esse levantamento, é que $D$. Quixote é "um poema sobre a liberdade" (COSERIU, 2007, p. 269) e, no conjunto da novela, a instabilidade dos nomes deve também ser interpretada como um momento de liberdade: somos livres para dar nomes às coisas porque todo nome corresponde a uma forma determinada de ver as coisas. O trágico é que as possibilidades de lutar pela liberdade são limitadas - ligadas à demência do herói - e abandonadas quando ele é vencido e curado da loucura.

Voltemos agora ao nosso ponto de partida: qual é a contribuição da forma e do contexto para a Linguística do Texto de Coseriu? A análise que o autor faz da novela $D$. Quixote revela que as formas linguísticas são pistas importantes para a interpretação do sentido. Poderíamos citar vários outros exemplos explorados por ele, mas basta mostrar a importância que a instabilidade dos nomes próprios tem para a interpretação da novela de Cervantes. Já a questão do contexto, apresentada de forma minuciosa enquanto formulação teórica, parece não ter um papel relevante na análise. Esse descompasso pode ser esclarecido a partir da discussão sobre a natureza do discurso literário e do discurso informativo (COSERIU, 2006).

Sendo o texto literário considerado o objeto prioritário da Linguística do Texto, por apresentar a linguagem em plena funcionalidade, vamos analisar inicialmente a contribuição da forma para a interpretação da linguagem literária. A posição de Coseriu sobre essa questão é bem clara. Segundo ele: 


\begin{abstract}
Aristóteles destacou na Física (II, 8-9) que onde existe causa final, esta é a causa determinante de todas as outras, inclusive da material (o material com que se faz algo): a estruturação deste material está determinada pela finalidade. Consequentemente, nos discursos poéticos, os procedimentos de expressão não são o determinante, mas o determinado, e temos que descobrir, então, por que se apresentam dessa forma: sem dúvida, porque uma expressão se apresenta como uma expressão bem sucedida quando observamos que corresponde exatamente a uma finalidade. (COSERIU, 2006, p. 54)
\end{abstract}

A escolha das formas nos textos literários é importante, mas não é a forma que define o texto literário. É significativo lembrar a crítica que Coseriu faz à posição de Jakobson em seu conhecido artigo "Linguística e poética” (COSERIU, 2007, p. 163-176) pela análise do slogan publicitário da campanha presidencial de Dwight Ike Eisenhower - I like Ike - como um exemplo de linguagem poética. Um slogan publicitário tem uma finalidade prática, que não se identifica com a finalidade da literatura e não se torna literário pelos recursos formais. Para Coseriu, a literatura não tem nenhuma finalidade exterior ou instrumental: "Na literatura a própria realidade é inventada e o discurso coincide com essa criação da realidade." (COSERIU, 2006, p. 56). Assim, a contribuição dos elementos formais na Linguística do Texto como hermenêutica do sentido está subordinada ao sentido do texto; as formas contribuem para que o texto seja bem sucedido em seu propósito geral, na expressão do sentido da obra nos diversos níveis (parágrafos, capítulos, obra). Na interpretação do texto literário as formas são relevantes, pois correspondem à materialização dos propósitos do autor.

Na perspectiva de Coseriu, a questão do contexto da obra literária é mais complexa, por qualquer ângulo que o analisemos: o momento histórico da produção, as representações do autor ou do leitor. Ao comparar o autor do texto informativo com o autor do texto literário, Coseriu adverte: "[...] o sujeito da obra literária é sempre um sujeito universal: é o Autor, com maiúsculas, e não um determinado indivíduo." (COSERIU, 2006, p. 57). Sobre a situação:

\footnotetext{
A situação do sujeito universal da obra literária (não do sujeito empírico, porque este também tem fome, tem frio e tem outras sensações) é eterna (o que vem a ser o mesmo, não é específica), mesmo no que diz respeito à técnica, mas que se encontra numa situação histórica, porque tem uma tradição de língua literária do idioma em que escreve ou uma tradição do gênero literário em que escreve; mas, enquanto obra que possa ser valorizada esteticamente e não como fato de cultura ou de tradição, esta obra é assituacional (COSERIU, 2006, p. 57).
} 
Costa, I. B. Forma e Contexto na Linguística do Texto de Eugenio Coseriu

Finalmente, sobre a representação dos interlocutores:

O sujeito da obra literária, no entanto, não se dirige a ninguém: $A$ Ilíada não é comunicação com alguém ou a alguém, mas a toda a humanidade e para todos os tempos; e o fato de se escrever isso em uma determinada língua não tem a menor importância: este é um modo de ser universal para todas as épocas e para todos os destinatários (COSERIU, 2006, p. 58).

As conviçções de Coseriu sobre o autor, a situação e o leitor do texto literário justificam a ausência de considerações sobre o contexto nas análises que faz. Pode-se concluir com segurança que, na hermenêutica do texto literário, só o contexto verbal é relevante: a relação do signo com os demais signos da língua, seja com os que poderiam ocorrer no seu lugar, seja os que $o$ antecedem e seguem na cadeia enunciativa.

Se na interpretação do discurso literário os elementos contextuais são praticamente irrelevantes, nos textos informativos eles têm um papel crucial. Nesses, a situação é fundamental, primeiramente para a determinação do sentido do texto, que Coseriu identifica com a designação, ou seja, com a referência à realidade extralinguística:

No discurso informativo não é que falte o sentido - de fato, todo discurso o tem -, mas que este coincide, como nos discursos deste tipo - em se tratando de comprovação -, com o significado da designação: "Diz as coisas como são.", cumprindo assim a norma (COSERIU, 2006, p. 57).

É relevante também para a identificação dos interlocutores: "O sujeito falante do discurso informativo é o sujeito empírico." (COSERIU, 2006, p. 57); "O sujeito falante do discurso informativo se dirige sempre e necessariamente a alguém, a um público que informa ou a quem comunica a informação: transmite informação a outros." (COSERIU, 2006, p. 58). Finalmente, o discurso informativo é situado historicamente: "A situação do sujeito do discurso informativo é sempre uma determinada situação histórica." (COSERIU, 2006, p. 57).

\section{CONCLUSÃO}

Após esta interlocução com a Linguística do Texto formulada por Coseriu, e retomando os pressupostos que consideramos no início do trabalho, fica claro que a grande diferença entre a Linguística do Texto que adotamos e a do autor está nos gêneros textuais tomados como objeto de análise. A 
divergência não está na oposição entre uma Linguística do Texto como gramática transoracional e uma Linguística voltada à hermenêutica do sentido, mas entre uma Linguística do Texto que tem como objeto a grande variedade de textos em circulação na sociedade e uma Linguística do Texto voltada prioritariamente para o texto literário.

As divergências não estão centradas nas categorias de análise nem na metodologia. A Linguística do Texto praticada hoje poderia incorporar boa parte dos pressupostos de Coseriu. O ponto central de divergência está na premissa adotada por ele de que a linguagem poética representa a linguagem em plena funcionalidade e de que os textos não literários operam uma redução das funções linguísticas.

Coseriu minimiza a importância dos fatores interacionais e contextuais para a construção do sentido dos textos na Linguística do Texto proposta como uma consequência lógica de tomar como objeto prioritário de análise as obras literárias caracterizadas pela universalidade e atemporalidade. Ao olharmos para a grande diversidade de textos em circulação em sociedades complexas e letradas, os fatores situacionais adquirem um estatuto bem diverso e o autor tem plena consciência disso, como mostra na comparação entre os textos informativos e os literários.

\section{RESUMO}

Este estudo tem como ponto de partida a discussão sobre o lugar dos estudos textuais nos níveis de funcionamento da linguagem a partir do modelo formulado por Coseriu. Como o autor admite a possibilidade de uma dupla posição do texto e, consequentemente, duas concepções divergentes de Linguística do Texto, a relação entre forma e contexto é examinada em cada uma delas. A concepção de Linguística do Texto como gramática transoracional, rejeitada pelo autor, contempla a sistematização dos recursos formais de que as línguas dispõem para a criação de textos, sem enfatizar o papel do contexto. A Linguística do Texto como hermenêutica do sentido tem como objeto prioritário o estudo de textos literários, caracterizados pela atemporalidade na relação autor-leitor; a partir dessa perspectiva, prioriza as relações internas ao texto e o contexto linguístico de uso dos signos. o contexto histórico da produção dos textos e sua relação com os aspectos formais só é enfatizado por Coseriu na comparação entre textos informativos e literários.

Palavras-chave: linguística do texto; forma; contexto; Coseriu. 


\begin{abstract}
This study discusses about the place of textual studies at the level of the language functioning from a model formulated by Coseriu. As the author admits the possibility of a double position of the text and, consequently, two diverging conceptions of textual linguistics, the relationship between form and context is examined in each one of them. The conception of Textual Linguistics transclausal grammar, refused by the author, considers the systematization of the formal resources, used by the languages to producing texts without emphasizing the context role. The Textual Languistics, as hermeneutics of sense, has the study of literary texts as its priority object, characterized by non-temporality on the author-reader's relationship. From this perspective the Textual Linguistics takes priority to the internal relationship to the text and the linguistic context of signs' use. The historic context of the text production and its relationship with the formal aspects is emphasized by Coseriu only in the comparison between informative texts and literary ones.

Keywords: textual linguistics; form; context; Coseriu.
\end{abstract}

\title{
REFERÊNCIAS
}

ADAM, Jean-Michel. Les textes: Types et prototypes . 4. ed. Paris: Nathan, 2001.

BAKHTIN, Mikhail. Estética da criação verbal. São Paulo: Martins Fontes, 1992.

CERVANTES DE SAAVEDRA, Miguel de. Dom Quixote de La Mancha. São Paulo: Abril Cultural, 1978.

COSERIU, Eugenio. Linguística del texto: Introducción a la hermenêutica del sentido. Edición de Óscar Loureda Lamas. Madri: Arco Libros, 2007.

Información y literatura. In: COSERIU, Eugênio; LOUREDA LAMAS, Óscar. Lenguaje $\bar{y}$ discurso. Navarra - Espanha: Ediciones Universidad de Navarra, (EUNSA), 2006.

; LOUREDA LAMAS, Óscar. Lenguaje y discurso. Navarra - Espanha: Ediciones Universidad de Navarra, (EUNSA), 2006.

КОСH, Ingedore Villaça. O texto e a construção do sentido. São Paulo: Contexto, 1997.

MARCUSCHI, Luiz Antônio. Os desafios da identificação do gênero textual nas atividades de ensino: propósitos comunicativos versus forma estrutural. Conferência apresentada no III SIGET. Universidade Federal de Santa Maria, 16-18 ago. 2005. (inédito)

Enviado em: 19/11/2009

Aceito em: 02/02/2010 